\title{
Building A Social Edition of the Devonshire Manuscript
}

\author{
CONSTANCE CROMPTON \\ DANIEL POWELL \\ University of Victoria \\ ALYSSA ARBUCKLE \\ University of Victoria \\ RAY SIEMENS \\ University of Victoria
}

University of British Columbia, Okanagan

with MAGGIE SHIRLEy University of British Columbia, Okanagan

and the DEVONSHIRE MANUSCRIPT EDITORIAL GROUP

This article describes the context and development of A Social Edition of the Devonshire Manuscript, a collaboratively created Wikibook edition of the sixteenth-century verse miscellany known as the Devonshire Manuscript (BL MS Add. 17,492). This project began in 2001 when Dr. Ray Siemens led a group of researchers in an exploration of how to create a digital edition of the Devonshire Manuscript. Since then, the project has transitioned through many forms and formats, and A Social Edition of the Devonshire Manuscript is the most recent output of these academic experiments. Of note, a print version of A Social Edition of the Devonshire Manuscript is forthcoming from Iter and Medieval and Renaissance Texts and Studies (MRTS).

Cet article retrace le contexte et le développement du projet A Social Edition of the Devonshire Manuscript, consistant en l'édition électronique (Wikibook) en collaboration d'un manuscrit du XVI siècle de mélanges poétiques connu sous le nom de Devonshire Manuscript (BL MS Add. 17 492). Ce projet a été initié en 2001, lorsque le Dr Ray Siemens a dirigé un groupe de recherche explorant les possibilités de publier une édition numérique du Devonshire Manuscript. Depuis, le projet a pris plusieurs formes, et celui intitulé A Social Edition of the Devonshire Manuscript en est sa forme la plus récente issues des diverses expériences du groupe. Il doit être souligné que A Social Edition of the Devonshire Manuscript, sera bientôt publié en version imprimée par Iter et les Medieval and Renaissance Texts and Studies (MRTS).

$\triangle$ Social Edition of the Devonshire Manuscript is an unconventional text in that it attempts to bring traditional scholarly editing practices and 
standards into conversation with comparatively recent developments in online social media environments. In doing so, the edition aims to embody contemporary editorial theories recognizing the inherently social form and formation of texts alongside the social practices of writing, revision, and editing that shaped the original production of the Devonshire Manuscript (BL MS Add. 17,492). Dating from the 1530 s to the 1540 s, the Devonshire Manuscript is a collaborative verse miscellany authored and compiled by a number of sixteenth-century contributors. ${ }^{1}$ We believe that, as an inherently collaborative text, the manuscript calls for an innovative approach to scholarly editing. In this article, we detail the content, context, process, and implications of A Social Edition of the Devonshire Manuscript. ${ }^{2}$

A Social Edition of the Devonshire Manuscript is an innovative project, but one with deep roots in ongoing Canadian scholarship on Renaissance literature, scholarly editions, and digital humanities prototyping. Much of this transdisciplinary work has taken place under the aegis of two groups: the Electronic Textual Cultures Lab (ETCL) at the University of Victoria and the Canada-wide Implementing New Knowledge Environments (INKE), both directed by Ray Siemens. ${ }^{3}$ The ETCL engages deeply with the study of textual communication in all its historical, present, and future forms. Alongside this research mandate, the ETCL serves as a Vancouver Island-based hub for regional, national, and global digital humanities work and training; the highly successful Digital Humanities Summer Institute (DHSI) held annually at the University of Victoria is perhaps the flagship initiative of the wider digital humanities community. ${ }^{4}$ With graduate student researchers, postdoctoral fellows, affiliated faculty, visiting speakers, and regular community events, the ETCL is a vibrant research collective engaged in the wider examinations of the types of intellectual issues prompted

1. Following Peter Beal's definition of a verse miscellany as "a manuscript, a compilation of predominantly verse texts, or extracts from verse texts, by different authors and usually gleaned from different sources" in A Dictionary of English Manuscript Terminology, 1450-2000 (London: Oxford University Press, 2008), 429. Beal lists the Devonshire Manuscript as a pertinent example of a verse miscellany (430).

2. The Devonshire MS Editorial Group, A Social Edition of the Devonshire MS (BL Add 17,492), Wikibooks, 5 November 2014, http://en.wikibooks.org/wiki/The_Devonshire_Manuscript.

3. Website of the ETCL, 5 November 2014, http://etcl.uvic.ca/. Website for INKE, 5 November 2014, http://inke.ca/.

4. Website for DHSI, 5 November 2014, http://dhsi.org/. 
by A Social Edition of the Devonshire Manuscript. As a research and prototyping initiative, INKE describes itself "as an interdisciplinary initiative spawned in the methodological commons of the digital humanities that seeks to understand the future of reading through reading's past and to explore the future of the book from the perspective of its history." ${ }^{5}$ Divided into two research areasmodelling and prototyping and interface design-INKE members interrogate the nature of textuality in the digital age. To date, the various INKE groups have produced a number of publications, sponsored several conferences, and built numerous digital tools and prototypes for scholarly use. ${ }^{6}$

As these brief synopses might indicate, the intertwining research communities present around the ETCL and INKE provide context for A Social Edition of the Devonshire Manuscript. The prototyping and consideration of what a digital, social, scholarly edition might look like is an expression of longstanding and well-funded Canadian research into the nature of the book in a digital age. It also attempts to put into practice Siemens's argument that social media environments may enable new editing practices, itself an argument formulated in an article emerging from the collaborative research environment of the ETCL.?

By publishing on Wikibooks (a partner site to Wikipedia focused on book-length projects) we emphasize the collective, social ethos of the original document itself. Throughout this process we have attempted to model the social scholarly edition and address the questions a social edition, and social editing, raise: How do we effectively integrate multiple communities with varying cultures and editorial standards while pushing the boundaries of editorial authority? How do we employ various social media platforms with different degrees of openness to ensure a safe space for numerous individuals and opinions? And how do we shift the power from a single editor who shapes the reading of any given text to a group of readers whose interactions and interpretations form a new method of making meaning out of primary source material? To attend to

5. “About," INKE, 5 November 2014, http://inke.ca/projects/about/.

6. For publications, see: http://inke.ca/projects/publications/; for featured tools and prototypes, see: http://inke.ca/projects/tools-and-prototypes/; for conferences see: http://inke.ca/skill/research-activities-engagement/. Accessed 5 November 2014.

7. Ray Siemens, with Meagan Timney, Cara Leitch, Corina Koolen, and Alex Garnett, and with the ETCL, INKE, and Public Knowledge Project (PKP) Research Groups, "Toward Modeling the Social Edition: An Approach to Understanding the Electronic Scholarly Edition in the Context of New and Emerging Social Media," Literary and Linguistic Computing 27.4 (2012): 445-61. 
these questions, this article begins with a description and consideration of the document itself-BL MS Add. 17,492. Next, we recount the processes involved with building a digital social edition of this idiosyncratic text. To conclude, we interrogate the affordances and drawbacks of digital scholarly editing in collaborative, Web 2.0 contexts.

\section{The multivalent text of the Devonshire Manuscript}

Acquired in 1848 by the British Museum, the Devonshire Manuscript contains approximately two hundred items (including complete lyrics, verse fragments, excerpts from longer works, anagrams, and other ephemeral jottings) on 198 pages (including endpapers) bound in a handwritten volume and inscribed in over a dozen hands by a coterie of men and women centred in the court of Queen Anne Boleyn. ${ }^{8}$ Despite steadily growing scholarly interest in the Devonshire Manuscript, no critical edition existed during the production of A Social Edition of the Devonshire Manuscript. ${ }^{9}$ The manuscript has long been valued as a source of Sir Thomas Wyatt's poetry, as he composed 129 of the 200 items in the manuscript (although they are not in his hand). These verses, in turn, have been transcribed and published by Agnes K. Foxwell, Kenneth Muir, and Patricia Thomson in their respective editions of Wyatt's poetry. ${ }^{10}$ Arthur

8. On the origins, early history, and enumeration of the Devonshire Manuscript, see especially Richard C. Harrier, The Canon of Sir Thomas Wyatt's Poetry (Cambridge, MA: Harvard University Press, 1975), 23-54; Raymond Southall, "The Devonshire Manuscript Collection of Early Tudor Poetry, 1532-41," Review of English Studies 15 (1964): 142-43; Paul Remley, "Mary Shelton and Her Tudor Literary Milieu," in Rethinking the Henrician Era: Essays on Early Tudor Texts and Contexts, ed. Peter C. Herman (Urbana: University of Illinois Press, 1994), 41, 47-48. See also Helen Baron, "Mary (Howard) Fitzroy's Hand in the Devonshire Manuscript," Review of English Studies: A Quarterly Journal of English Literature and the English Language 45 (1994): 324-29, and Elizabeth Heale, "Women and the Courtly Love Lyric: The Devonshire MS (BL Additional 17492)," Modern Language Review 90.2 (1995): 297-301.

9. Elizabeth Heale's edition, The Devonshire Manuscript: A Women's Book of Courtly Poetry (Toronto: Centre for Reformation and Renaissance Studies, 2012), is based on a regularized version of the Devonshire Manuscript Editorial Group transcriptions of the manuscript and was published in October 2012.

10. Agnes K. Foxwell, ed., The Poems of Sir Thomas Wiat (London: University of London Press, 1913); Kenneth Muir, ed., Collected Poems of Sir Thomas Wyatt (London: Routledge and Kegan Paul, 1949); Kenneth Muir and Patricia Thomson, eds., Collected Poems of Sir Thomas Wyatt (Liverpool: Liverpool University Press, 1969). Many of the remaining poems, unattributed to Wyatt, have been transcribed 
F. Marotti argues that the author-centred focus of these editions "distorts [the] character" of the Devonshire Manuscript in two ways: "first, it unjustifiably draws the work of other writers into the Wyatt canon, and, second, it prevents an appreciation of the collection as a document illustrating some of the uses of lyric verse within an actual social environment." ${ }^{11}$ The Devonshire Manuscript is much more than an important witness in the Wyatt canon; it is also a snapshot of the scribal practices of male and female lyricists, scribes, and compilers in the Henrician court, as well as the first example of men and women writing together in sustained fashion in English.

A Social Edition of the Devonshire Manuscript seeks to publish the contents of the original manuscript in their entirety, move beyond the limitations of an author-centred focus on Wyatt's contributions in isolation, and concentrate on the social, literary, and historical contexts in which the volume is situated as a unified whole. In doing so, we are guided by the theories of textuality put forth by D. F. McKenzie and Jerome McGann, among others. McGann believes that "nonauthorial textual determinants" should be considered alongside authorial presence to include in our critical gaze "other persons or groups involved in the initial process of production," as well as the phases, stages, means, modes, and materials of this initial production process. ${ }^{12}$ McKenzie's "sociology of texts" further extends this idea by arguing for the significance of the material form of a text and its ability to affect the text's meaning. ${ }^{13}$ These theories of textual production have, for some time, prompted critics to reevaluate the notion of authorship in order to account for nonauthorial (but nevertheless

and published in Kenneth Muir, "Unpublished Poems in the Devonshire Manuscript," Proceedings of the Leeds Philosophical and Literary Society 6 (1947): 253-82. George Frederick Nott's important early two-volume edition, The Works of Henry Howard, Earl of Surrey, and of Sir Thomas Wyatt, the Elder (London: T. Bensley, 1815), does not include diplomatic transcriptions of verses.

11. Arthur F. Marotti, Manuscript, Print, and the English Renaissance Lyric (Ithaca: Cornell University Press, 1995), 40. Nott's misguided statement, that the manuscript "contains Wyatt's pieces almost exclusively" (2:vii), or Muir's comment, "it is not always easy to decide whether a poem [in the manuscript] is written by a successful imitator or by Wyatt himself in an uninspired mood" ("Unpublished Poems," 253), are characteristic of the sort of dismissive author-centric views taken to task by Marotti.

12. Jerome McGann, "The Monks and Giants: Textual and Bibliographical Studies and the Interpretation of Literary Works," in The Beauty of Inflections: Literary Investigations in Historical Method and Theory (Oxford: Oxford University Press, 1988), 79, 82. See also McGann's earlier study, A Critique of Modern Textual Criticism (Chicago: Chicago University Press, 1983).

13. D. F. McKenzie, Bibliography and the Sociology of Texts (London: British Library, 1986). 
deeply significant) organizers, contributors, and collaborators. Arthur Marotti's assertion that "literary production, reproduction, and reception are all socially mediated, the resulting texts demanding attention in their own right and not just as legitimate or illegitimate variants from authorial archetypes" further illustrates the changing landscape of editorial theory. ${ }^{14}$

In keeping with the theoretical positions of McGann, McKenzie, and Marotti, A Social Edition of the Devonshire Manuscript aims to preserve the socially mediated textual and extra-textual elements of the manuscript that have been elided or ignored in previous transcriptions. These "paratexts" make significant contributions to the meaning and appreciation of the manuscript miscellany and its constituent parts: annotations, glosses, names, ciphers, and various jottings; the telling proximity of one work to another; significant gatherings of materials; illustrations entered into the manuscript alongside the text; and so forth. ${ }^{15}$ In recognizing the various paratextual elements of the text, we challenge (even at a basic level) what it means to transcribe and edit the Devonshire Manuscript.

The manuscript can be roughly divided into the following types of content:

- $\quad$ short courtly verses by Sir Thomas Wyatt (129 items, 66 unique to the manuscript) and Henry Howard, Earl of Surrey (one item);

- $\quad$ verses attributed to Lady Margaret Douglas (two items), Richard Hattfield (two items), Mary Fitzroy (née Howard) (one item), Lord Thomas Howard (three items), Sir Edmund Knyvett (two items), Sir Anthony Lee (one item [“A. I." has three items]), and Henry Stewart, Lord Darnley (one item);

- $\quad$ transcribed portions of medieval verse by Geoffrey Chaucer (eleven items), Thomas Hoccleve (three items), and Richard Roos (two items);

- transcriptions of the work of others or original works by prominent court figures such as Mary Shelton, Lady Margaret Douglas, Mary (Howard) Fitzroy, Lord Thomas Howard, and perhaps Queen Anne Boleyn;

- $\quad$ some thirty-one unidentified or unattributed pieces. ${ }^{16}$

14. Marotti, 212.

15. We have interpreted "paratext" broadly, as articulated in Gérard Genette, Paratexts: Thresholds of Interpretation, trans. Jane E. Lewin (Cambridge: Cambridge University Press, 1997).

16. Scholars have only cautiously asserted an approximate number of items preserved in the Devonshire Manuscript: "the number of poems in the manuscript can only be given as approximately 184" (Southall, 
As we will discuss below, these multiple contributors often comment on and evaluate each other's work through marginal notation and drawing, in-line interjection, exchanging epistolary verse, and selectively altering transcribed texts.

We follow Helen Baron's attribution of hands in the Devonshire Manuscript. ${ }^{17}$ Of the roughly twenty hands, including those individuals named above, some are even and regular while others are idiosyncratic and variable. The inconstancy of the handwriting has historically made the transcription of the entire manuscript exceptionally difficult, thereby impeding widespread research on the text. Of the two hundred items, approximately 140 entries are copies of pre-existing or contemporary works and bear the signs of copying from other texts. The majority of the pieces may reflect the work of local amanuenses and secretaries with little professional regard for the expected standards of a presentation-copy manuscript. A full half of the manuscript's scribes (Hands 1 , $3,4,5,6,8,9,10,11$, and Mary (Howard) Fitzroy [MF]) dedicate themselves to copying only extant, pre-existing pieces; another five (Hands 1.1, 2, 7, Thomas Howard 2 [TH2], and Margaret Douglas [MD]) enter a mix of copied, extant material and material that appears to be unique to the manuscript. The remaining five (Hands 12, 13, Henry Stuart [HS], Mary Shelton [MS], and Thomas Howard 1 [TH1]) enter only original materials. The work of the ten hands entering potentially original material to the manuscript amounts to forty-five pieces (fifteen identified and/or attributed). The complexity, density, and interconnection of these multiple layers and many authors make the Devonshire Manuscript an ideal test case for experimentations in social editing.

143); "the manuscript preserves about 185 items of verse, but it is impossible to obtain an exact figure as many of these are fragments, medieval extracts or the like, and others are divided up differently by various editors" (Remley, 47). Ethel Seaton identified the medieval origin of the Richard Roos texts in "The Devonshire Manuscript and its Medieval Fragments," Review of English Studies 7 (1956): 55-56. Richard Harrier first noted the use of William Thynne's 1532 edition of Chaucer as the source for that poet's verse in the Devonshire Manuscript in "A Printed Source for the 'Devonshire Manuscript," Review of English Studies 11 (1960): 54.

17. See "The Devonshire Manuscript/Detailed Hand List Hand," last modified 16 May 2012, http:// en.wikibooks.org/wiki/The_Devonshire_Manuscript/Detailed_Hand_List_Hand_1. The most recent examination of the hands in D is that of Helen Baron, especially Table 1 in "Mary (Howard) Fitzroy's Hand." See also the earlier findings in Edward A. Bond, "Wyatt's Poems," Athenaeum 27 (1871): 654-55. Where the transcribers differ from Baron's attribution, the project's identification is noted in the underlying TEI markup, available at http://hcmc.uvic.ca/ etcl/Devonshire_Manuscript_poems.zip. 
The collaborative, social editing processes of the original contributors are visibly evident throughout the manuscript. Besides writing epistolary verse, contributors to the manuscript interacted with one another through annotation. Occasionally, these marginal responses appear quite personal in nature. They include responses that evaluate the quality of certain lines or cross out one word and insert another. In doing so, the annotations reveal the compilers' intense social engagement and editorial collaboration. For example, the text of the poem "Suffryng in sorow in hope to attayn" (fol. 6v-7r), written in a male voice appealing for the love of a lady, is annotated in the left margin. Lady Margaret Douglas writes "fforget thys," to which Mary Shelton responds, "yt ys wor[t]hy" (fol. 6v). "Suffryng in sorow" and "desyryng in fere [fear]," the poet pleads for his unnamed addressee to "ease me off my payn" (fol. 6v, 11. 1-2, 4).

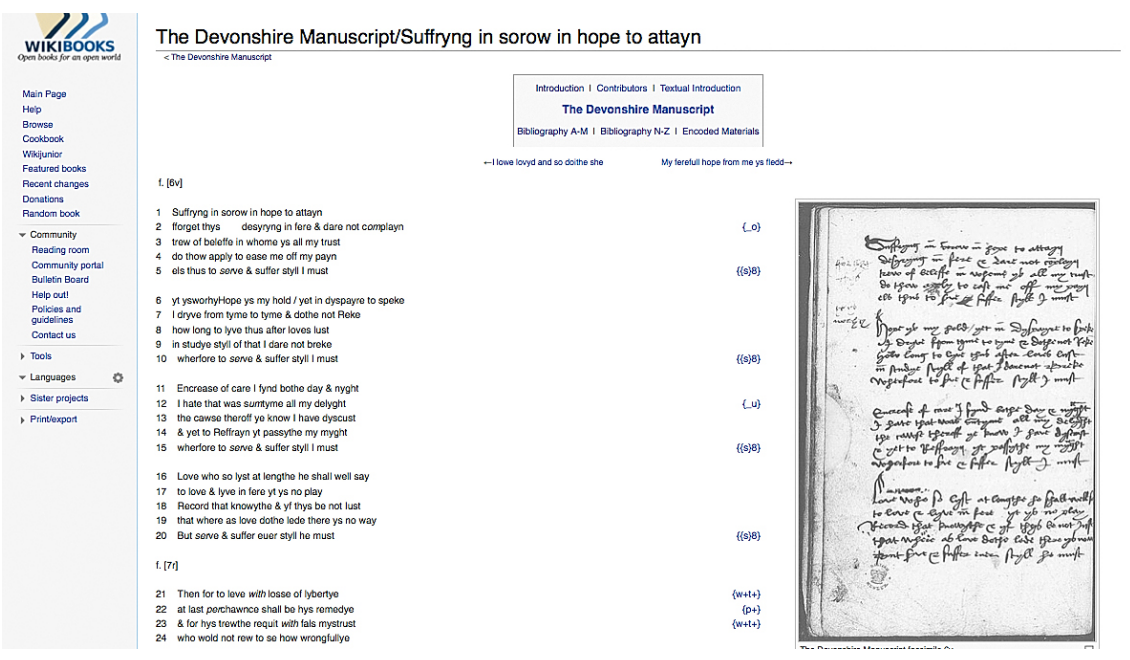

Figure 1: "Suffrying in sorow in hope to attayn" (fol. 6v-7r) in A Social Edition of the Devonshire Manuscript

While its authorship within the coterie remains debated, the acrostic of the stanzas suggests that Shelton is the intended recipient: the overemphasized first letter of its seven stanzas spells out "SHELTVN."18 The scribal

18. The poem is entered in the Devonshire Manuscript by an unidentified hand (H2), and is also preserved in the Blage Manuscript (Trinity College, Dublin, MS 160, fol. 159r). Modern editors of 
annotations, which in some analyses may refer only to the quality of the verse, could therefore take on a more profound and personal meaning, as Douglas recommends rejecting the poem and its suit ("fforget thys"), but Shelton contradicts this advice with "yt ys wor[t]hy." At the end of the poem, Shelton adds a comment that has been variously transcribed as "ondesyard sarwes / reqwer no hyar," "ondesyrid favours / deserv no hyer," or perhaps "ondesyard fansies / requier no hyar."19 The transcription poses an interesting editorial crux: "sarwes" might be read as "service" or "sorrows." ${ }^{20}$ Likewise, "hyar" may be read as "hire" or "ear."

Wyatt's poems commonly attribute the poem to him (Foxwell, 1:257-58; Muir, Collected Poems, 96-97; Muir and Thomson, Collected Poems, 176-77; Nott, 2: 590). However, this attribution has not been universally accepted: Harrier argues that the poem "must be excluded from the Wyatt canon" since it "may be by Thomas Clere" ("Printed Source," 41, 45), and Joost Daalder silently excludes the poem from his edition, Collected Poems (London: Oxford University Press, 1975). Julia Boffey has argued the author is Shelton, mistaking Shelton's signed comment at the end of the poem as an attribution, in "Women Authors and Women's Literacy in Fourteenth- and Fifteenth-century England," in Women and Literature in Britain 1150-1500, ed. Carol M. Meale (Cambridge: Cambridge University Press, 1996), 173.

19. The first transcription as per Baron, 331; Remley gives "ondesyerd" (50). The second as per Foxwell (1: 258). The third as per Heale ("Women and the Courtly Love Lyric," 301). Heale also gives "ondesiard fansies / requier no hiar" in Wyatt, Surrey and Early Tudor Poetry (London: Longman, 1998), 43, and "ondesyred fansies / require no hyar" in "Desiring Women Writing': Female Voices and Courtly 'Balets' in Some Early Tudor Manuscript Albums," in Early Modern Women's Manuscript Writing: Selected Papers from the Trinity/Trent Colloquium, ed. Victoria Elizabeth Burke and Jonathan Gibson (Aldershot: Ashgate, 2004), 21.

20. "Searwes" (device) is also possible, but unlikely. Alternatively rendering the word as "fansies" or "favours" is less problematic, but equally less probable.

21. S. P. Zitner argues, "[w] hether Mary Shelton was saying that undesired service (attention) required no hire or that undesired sorrows required no ear, the response is pretty much the same in tone and substance," in "Truth and Mourning in a Sonnet by Surrey," English Literary History 50.3 (1983): 513. While this comment may be a "remarkable example of an overtly critical rejoinder to a courtly lyric" written in the spirit described by Zitner, Remley argues that "it seems equally probable that her words are meant ironically"; that they offer a "private recognition of the absurd spectacle of a man determined to get his way through protestations of extreme humility" (50). Similarly, Heale contends such "unsympathetic replies may be part of the conventional exchange of courtly verse" and might be offered in jest, as "such jesting offered some opportunities for female subject positions that seem to have appealed to the women using the manuscript" ("Desiring Women Writing," 21). 


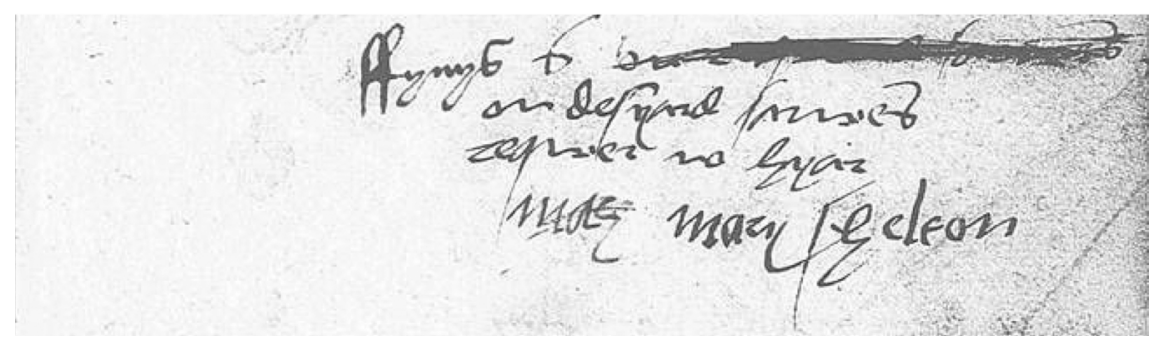

Figure 2: The disputed comment at the end of "Suffrying in sorow in hope to attayn" (fol. 6v-7r) in A Social Edition of the Devonshire Manuscript

Although the precise intentions behind Shelton's annotations and commentary remain obscure, their potential importance to the meaning and interpretation of the verse cannot be disputed. These types of interactions reoccur throughout the document, offering us an image of a deeply personal-but also interpersonal-set of socio-textual relationships.

In this, the Devonshire Manuscript reflects its compositional origins and circulation within the early Tudor court of Henry VIII, a group that was profoundly concerned with public and private performances of political loyalty and submission. ${ }^{22}$ As Marotti notes, courtly manuscript miscellanies and poetic anthologies "represent the meeting ground of literary production and social practices." ${ }^{23}$ The Devonshire Manuscript contains numerous examples of this concept, especially in the form of epistolary verse and scribal annotation as outlined above. Proximity and placement of poems often bear further significance. The poem "My ferefull hope from me ys fledd" (fol. 7v), for instance, signed "fynys quod n[o]b[od]y," [the end, says nobody] is answered by the poem immediately following on the facing leaf, "Yowre ferefull hope cannot prevayle" (fol. 8r), in turn signed "fynys quod s[omebody]" [the end, says somebody]. While this kind of playful imitation and formal echoing does not strictly rely on the relative proximity of the poems in the manuscript, the effect is more immediately apparent and more visually striking when the poems

22. Alistair Fox writes, "[o]ne striking phenomenon about early Tudor literature is that it was almost invariably concerned with politics, either directly or indirectly, and that this political bearing had a major impact on the nature of its literary forms." "Literary Patronage: The System and Its Obligations," in Politics and Literature in the Reigns of Henry VII and Henry VIII (Oxford: Basil Blackwell, 1989), 3.

23. Marotti, 212. 
are placed, as they are, on facing leaves-itself a fact obscured by the layout of our digital edition. ${ }^{24}$ Poetry became yet another venue for the performance of public and private roles within the royal court, and the Devonshire Manuscript reflects this oscillation between public and private, personal and communal: within its pages, the private became public, the public was treated as private, and all was political. In addition to examining the volume as "a medium of social intercourse," ${ }^{25}$ other aspects of the Devonshire Manuscript-its multilayered and multi-authored composition, its early history and transmission, the ways in which its contents engage with and comment directly on contemporary political and social issues-invite further investigation and demand consideration while making critical assessments.

Alongside these critical realizations, the feminist turn in manuscript studies has caused scholars to stress the importance of the Devonshire Manuscript and its production practices (compilation, annotation, copying, et cetera) to women's literary history. ${ }^{26}$ To effectively investigate the role of

24. The teasing blend of jest and earnestness in this pair of unattributed poems points to the role of much of the content in the manuscript as participating in the courtly "game of love." See John Stevens, Music \& Poetry in the Early Tudor Court (Cambridge: Cambridge University Press), 154-202; see also Roger Boase, The Origin and Meaning of Courtly Love: A Critical Study of European Scholarship (Manchester: Manchester University Press, 1977); David Burnley, Courtliness and Literature in Medieval England (New York: Longman, 1998); and Bernard O'Donoghue, The Courtly Love Tradition (Manchester: Manchester University Press, 1982). It is also worth noting that in the manuscript, both "nobody" and "somebody" appear to have been partially erased-a fact clearly visible in our edition's facsimile images.

25. Harold Love and Arthur F. Marotti, "Manuscript Transmission and Circulation," in The Cambridge History of Early Modern English Literature, ed. David Loewenstein and Janel Mueller (Cambridge: Cambridge University Press, 2002), 63.

26. Representative scholarship includes Elaine V. Beilin, Redeeming Eve: Women Writers of the English Renaissance (Princeton: Princeton University Press, 1987); Margaret J. M. Ezell, Writing Women's Literary History (Baltimore: Johns Hopkins University Press, 1993); Ezell, Social Authorship and the Advent of Print (Baltimore: Johns Hopkins University Press, 1999); Barbara K. Lewalski, Writing Women in Jacobean England (Cambridge, MA: Harvard University Press, 1993); Kim Walker, Women Writers of the English Renaissance (New York: Twayne, 1996); and Wendy Wall, The Imprint of Gender: Authorship and Publication in the English Renaissance (Ithaca: Cornell University Press, 1993). See also the following representative essay collections: Anne M. Haselkorn and Betty S. Travitsky, eds., The Renaissance Englishwoman in Print: Counterbalancing the Canon (Amherst: University of Massachusetts Press, 1990); Margaret P. Hannay, ed., Silent but for the Word: Tudor Women as Patrons, Translators, and Writers of Religious Works (Kent: Kent State University Press, 1985); Susanne Woods and Margaret P. Hannay, 
women in the production and circulation of literary works, Margaret J. M. Ezell has persuasively proposed that the definition of "authorship" needs to be reexamined and broadened. ${ }^{27}$ Ezell's study of women's miscellanies demonstrates that these acts of preservation and compilation often serve to reinforce religious and political loyalties and to "cement social bonds during times of duress" within female literary circles. ${ }^{28}$ In a similar vein, Elizabeth Clarke notes that " $[\mathrm{c}]$ ompilation, rather than authorship of the writing in a document," was the "dominant literary activity among women who could read and write" in the early modern period. ${ }^{29}$ This is certainly true in the case of the Devonshire Manuscript, where women were, for the most part, directly responsible for the compilation and copying of the predominantly male-authored contents of the anthology. Some of the lyrics demonstrate close female friendship-Mary Shelton and Margaret Douglas kept close company, evidenced by the fact that Shelton's hand often immediately follows Douglas's - and these lyrics are now understood to have a definite subversive meaning for a select group of individuals. ${ }^{30}$ Like any of the other "nonauthorial" textual determinants described above, compilation is inarguably an act of mediation. The selection of verses to be recorded, the manner in which they are entered, and their relative position to one another all contribute to the total meaning of the texts, individually and as a collection. Verses entered

Teaching Tudor and Stuart Women Writers (New York: MLA, 2000); Helen Wilcox, ed., Women and Literature in Britain, 1500-1700 (Cambridge: Cambridge University Press, 1996); Mary E. Burke, Jane Donawerth, Linda L. Dove, and Karen Nelson, eds., Women, Writing, and the Reproduction of Culture in Tudor and Stuart Britain (Syracuse: Syracuse University Press, 2000).

27. Margaret Ezell, "Women and Writing," in A Companion to Early Modern Women's Writing, ed. Anita Pacheco (Oxford: Blackwell, 2002), 79.

28. Ezell, "Women and Writing," 86.

29. Elizabeth Clarke, "Women's Manuscript Miscellanies in Early Modern England," in Teaching Tudor and Stuart Women Writers, ed. Susanne Woods and Margaret P. Hannay (New York: MLA, 2000), 53.

30. Baron, 328. Kathryn DeZur notes that early modern women's participation in circulating love lyrics might also indicate "a possible site of resistance to the idealized cultural paradigm of women as chaste, silent, and obedient." See “'Vaine Books' and Early Modern Women Readers," in Reading and Literacy in the Middle Ages and Renaissance, ed. Ian Frederick Moulton, Arizona Studies in the Middle Ages and the Renaissance (Turnhout, Belgium: Brepols, 2004), 111. The Continental trend of courtly love made it fashionable for noble ladies at Henry VIII's court to compile miscellanies. Regardless, DeZur emphasizes that the tension between Christian values and courtly expectations meant that a woman's demeanour was always under scrutiny. 
into the manuscript may have been selected on the basis of their popularity at court-perhaps accounting for the disproportionate number of Wyatt poems represented-or for more personal reasons. Some, as recent scholarship has drawn attention to, were not simply selected and copied, but adapted and actively revised to suit specific purposes. The Devonshire Manuscript records the seemingly normal practices of compilation, revision, amanuensis, and composition between and among upper-class Tudor women.

The Devonshire Manuscript, then, is a rich, complex document. With its collection of courtly lyrics, pastiche of medieval and contemporary poetry, density of textual voices, and often-uncertain authorship and attribution, the manuscript demonstrates how textual production and interpretation were foundational to those reading and writing within this Tudor coterie. By paying heed to the various items in and around the verses-the annotations, order of leaves, and social context-one may obtain a fuller understanding of various source texts and its various actors. We have argued elsewhere, and repeat here, that the physical and social elements of the Devonshire Manuscript lend themselves to digital editing and publication processes that more readily represent the manifold nature of the volume than publication in a print environment is able to do. ${ }^{31}$ A Social Edition of the Devonshire Manuscript focuses on the editorial and scribal practices that inform the context and production of the Devonshire Manuscript. By shifting our own editorial process into an environment representative of the inherent collaborative sociality of this text, A Social Edition of the Devonshire Manuscript hearkens back to the multiauthor roots of the text itself. In the following section, we focus on the specifics of A Social Edition of the Devonshire Manuscript, as well as explore the benefits (and drawbacks) of building a scholarly edition on the Wikibooks platform.

\section{Building a social edition}

In order to build a scholarly edition on the principles of open access and editorial transparency (in both production and dissemination), we have integrated early modern content and scholarly editing practices with webbased environments maintained by established social and social-editorial 
communities-most notably on Wikibooks, a cross-section of intellectual research activity and the social media practices that define Web 2.0. ${ }^{32}$ Early on, Web 2.0 was described as internet technologies that allow users to be active authors rather than simply readers or consumers of web content. ${ }^{33}$ Now, the term is most frequently associated with social media platforms, wikis, and blog applications. As Tim Berners-Lee remarks, the internet was originally developed for workers to collaborate and access source documents; with wiki and Web 2.0 technology, it is now returning to its roots. ${ }^{34}$ The successful group of Wikimedia projects (Wikipedia, Wikibooks, Wikiquote, et cetera) emphasizes the importance of multi-authored and multi-edited endeavours. In doing so, Wikibooks instantiates earlier theoretical arguments that texts are created by a community of individuals; as Marotti argues, "production, reproduction, and reception are all socially mediated." ${ }^{35}$ To put this into practice, we extended our editorial conversations into multiple pre-existing Web 2.0 and social media platforms, including Twitter, blogs, Wikibooks discussion pages, dedicated Renaissance and early modern online community spaces, and Skype-enabled interviews with our advisory group. In creating A Social Edition of the Devonshire Manuscript we bring both Web 2.0 and current editorial theories of social textuality and community editing into closer focus. What is the outcome of scholarly editing if, like the originary Devonshire Manuscript contributors, we understand and enact the editionbuilding process as inherently collaborative? In what follows we offer a brief overview of the methods, process, and thinking that led to the Wikibook instantiation of A Social Edition of the Devonshire Manuscript.

32. Wikibooks is a Wikimedia project that continues the aim of Wikipedia; namely, to encourage, develop, and disseminate knowledge in the public sphere. Wikibooks differs from other Wikimedia projects in that it is primarily designed for facilitating collaborative open-content textbook building.

33. See Darcy DiNucci, “Fragmented Future,” Print 53 (April 1999): 32, 221-22.

34. In Simon Mahony, "Research Communities and Open Collaboration: The Example of the Digital Classicist Wiki," Digital Medievalist 6 (2011): n.p.

35. Marotti, 212. 


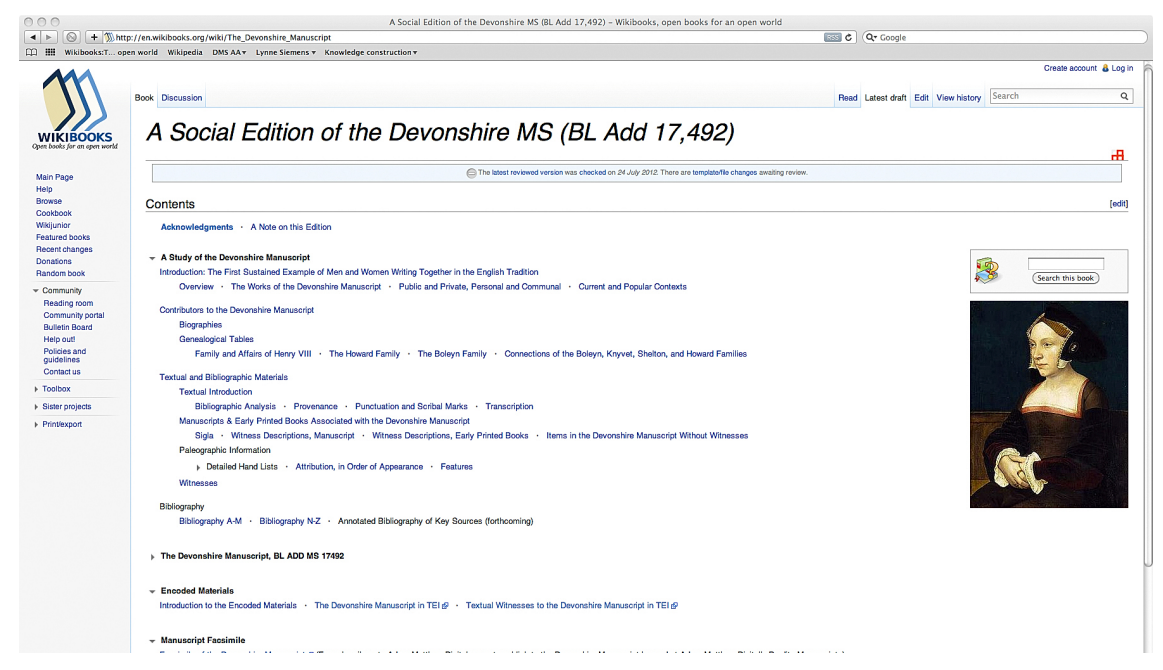

Figure 3: The homepage and table of contents of $A$ Social Edition of the Devonshire Manuscript

Perhaps more than any other editorial choice, the iterative publication of A Social Edition of the Devonshire Manuscript departed most clearly from traditional scholarly editing practices. In effect we have published (or are in the perpetual process of publishing) two versions of the edition: a PDF version, distributed to the project's advisory board; and a version housed on the publiclyeditable Wikibooks. We are also currently working with multiple publishing partners to produce versions of the edition in other mediums: an SQL-backed edition on Iter: Gateway to the Middle Ages and Renaissance; an e-reader edition designed for tablets; and a print edition, published by the Medieval and Renaissance Text Society. Taken together, these multiple platforms can meet the needs of a broad and varied readership while, for the most part, growing organically out of a central set of texts and practices. These versions were planned to productively inform and influence each other's development, with cross-pollination of editorial input across platforms.

The Wikibook edition pushes the limits of what a print edition can realistically achieve-including in sheer size. Even if the manuscript facsimile pages and the XML files were excluded, A Social Edition of the Devonshire Manuscript 
would run to over five hundred standard print pages. ${ }^{36}$ In addition to a general and textual introduction, the online edition includes extensive hand sample tables that open our paleographic attribution process to public scrutiny; witnesses that reflect the poem's textual legacy; biographies and genealogical diagrams that clarify the relationship between the manuscript's sixteenth-century compilers; and an extensive bibliography of quoted and related sources. Courtesy of Adam Matthew Digital, we have also included the facsimile image of each page of the manuscript alongside transcribed content and explanatory notes. Going further, the discussion sections on each wiki page allow conversation on each item. The Wikibook edition extends the social context of the Devonshire Manuscript by providing a space for ongoing discussion and collaboration.

Editorial processes of A Social Edition of the Devonshire Manuscript began long before selecting Wikibooks as a publication platform. In 2001, work on a digital edition of the manuscript began with a more recognizably traditional scholarly activity: primary source transcription. The base transcription is based on examination of both the original document at the British Library and a microfilm of the Devonshire Manuscript, also provided by the British Library. Members of the Devonshire Manuscript Editorial Group (or DMSEG, a team made up of scholars, postdoctoral fellows, graduate researchers, and programmers, ${ }^{37}$ working with two publishers, ${ }^{38}$ an editorial board, ${ }^{39}$ and self-

36. The DMSEG did, in fact, export the Wikibook edition to print format in summer 2013; the twovolume, hardback edition is approximately one thousand pages.

37. Ray Siemens, Karin Armstrong, Barbara Bond, Constance Crompton, Terra Dickson, Johanne Paquette, Jonathan Podracky, Ingrid Weber, Cara Leitch, Melanie Chernyk, Brett D. Hirsch, Daniel Powell, Alyssa Anne McLeod, Alyssa Arbuckle, Jonathan Gibson, Chris Gaudet, Eric Haswell, Arianna Ciula, Daniel Starza-Smith, and James Cummings, with Martin Holmes, Greg Newton, Paul Remley, Erik Kwakkel, Aimie Shirkie, and the INKE research group.

38. Iter, a not-for-profit consortium dedicated to the development and distribution of scholarly Middle Age and Renaissance online resources in partnership with Medieval and Renaissance Texts and Studies and Adam Matthew Digital, a digital academic publisher.

39. Robert E. Bjork (Director, Arizona Center for Medieval and Renaissance Studies; Arizona State University), William R. Bowen (Chair) (Director, Iter; University of Toronto Scarborough), Michael Ullyot (University of Calgary), Diane Jakacki (Georgia Institute of Technology), Jessica Murphy (University of Texas at Dallas), Jason Boyd (Ryerson University), Elizabeth Heale (University of Reading), Steven W. May (Georgetown College), Arthur F. Marotti (Wayne State University), Jennifer Summit (Stanford University), Jonathan Gibson (Queen Mary, University of London), John Lavignino (King's College London), and Katherine Rowe (Bryn Mawr College). 
selected members of the public) prepared and transcribed (in a blind process) two independent transcriptions from the microfilm. The transcribers collated the two paper copies manually, and the resultant rough text was resolved as far as possible using expanded paper prints and enlarged images. Their transcriptions were largely in accord with one another. Remaining areas of uncertainty were resolved with manual reference to the original document itself. This final, collated transcription forms the textual basis for A Social Edition of the Devonshire Manuscript, the basis of all editorial activity.

Following this process, the team then encoded the text in XML according to Text Encoding Initiative (TEI) guidelines. ${ }^{40}$ While encoding, the team upheld principles of consistency and accountability. Even if the team discovered a choice to be less than optimal, they continued in that pattern until the text was complete. Rather than employ varying practices, consistently encoding the entire manuscript in XML allowed for global changes that could be, and indeed were, made after the conclusion of the initial encoding. ${ }^{41}$ Furthermore, while encoding, the team maintained regular documentation to ensure that neither the original encoder nor any subsequent encoder would lack a basis from which to proceed. Another practice employed was to encode the manuscript by building layers of TEI in phases. The manuscript was completely encoded at a conservative level before commencing the second phase. The second layer of encoding, complete with annotations and regularizations, deepened, clarified, and augmented the first. This tiered process also allowed for the encoding of of doodles, anagrams, and other non-textual materials found within the manuscript.

Although the project began in 2001, the social edition on Wikibooks started with the formation of an advisory group in 2010. Throughout the production of A Social Edition of the Devonshire Manuscript, we consulted and conducted qualitative interviews with members of this advisory group to gather their perspectives on the content of the evolving edition. Forming an advisory group provided a unique opportunity to invite potential users and reviewers to shape the process and products associated with the social edition. As the final step before moving the text to Wikibooks, the members of the DMSEG

40. TEI provides a standard for encoding electronic texts. By encoding a text in XML under TEI guidelines, one renders the text substantially more searchable, categorizable, and preservable.

41. Please note that these global changes were not questions of textual transcription, but of encoding patterns and standards. 
working in the ETCL prepared a static digital edition of the manuscript. This fixed edition served as a base text against which our international advisory group of early modern and Renaissance scholars could compare the Wikibook edition as it evolved.

Before deciding on Wikibooks as a platform, the team had considered hosting the edition on a stand-alone site. In response to public interest in the project, coupled with the team's investment in emerging public knowledge communities, we instead developed a two-pronged strategy: as a control we produced a static PDF version of the edition, and as a variable we moved the same content onto a Wikimedia platform. Most famous for Wikipedia, Wikimedia is a small non-profit foundation responsible for management, fundraising, and technological development of Wikipedia, Wikibooks, Wikisource, Wiktionary, and a number of other projects. Volunteer editors contribute and moderate the content of all projects with self-developed norms and systems of oversight. We considered Wikisource, Wikibooks, and Wikipedia as platforms, eventually deciding to mount our edition in Wikibooks. Acknowledging the dedicated community already engaged in Wikimedia, we sought to discover Wikibooks' affordances for the scholar. Even though Wikipedia has far more editors, Wikibooks is purposefully structured to support the book-like form. And although Wikisource appears as a more appropriate environment for an edition, publishing A Social Edition of the Devonshire Manuscript on Wikisource would have disallowed the inclusion of any and all scholarly material outside the transcription itself-including paleographic expansions, appendices, notes, and bibliographies. With a book-like resource as our end goal, we produced a scholarly and peer reviewed edition in Wikibooks that also enables citizen scholars to access, contribute, and annotate material. Crucially, Wikibooks also archives each change in any content, allowing us to track reversions and revisions to the text.

In order to keep the editorial and encoding process transparent, the Wikibook edition includes links to the baseline XML-encoded transcription. In addition to being able to use the XML for their own projects, readers conversant with XML can see the encoder's TEI-based editorial choices. Anyone can download this XML and continue working with the XML in any way they see fit, allowing the project to potentially evolve in unanticipated ways. ${ }^{42}$ With the firm 
foundation of documented encoding, all those working with the document can refer to, build on, or adapt the project's foundation. Readers can compare our transcriptions to the facsimiles included on each page of the Wikibook edition and are free to contest (and even alter) our regularizations or corrections.

In November 2011, ETCL-based members of the DMSEG began converting the TEI-encoded text into Wikimarkup, the unique language designed for wiki publication. The team then moved the text, appendices, glosses, commentary, and textual notes into Wikibooks. Wikibooks, like Wikimedia and institutional scholarship at large, has its own self-governing editorial culture, and $A$ Social Edition of the Devonshire Manuscript received attention from Wikibooks' existing editorial community. Since then, the ETCL team has amplified the base text with additional images of the manuscript, witness transcriptions, an extensive bibliography, and the XML files containing the encoded transcription of the manuscript. Consequently, the Wikibook became a hybridized editionresearch environment for both early modern scholars and Tudor enthusiasts. Various authors have written on these phenomena, and on the value of employing wikis as collaborative research or authoring platforms; best practice standards and protocols have developed as an increasing number of researchers (both academic and not) become versed in Wikipedia methods. We have consciously developed A Social Edition of the Devonshire Manuscript, a scholarly Wikibook edition, with these practitioners, priorities, and standards in mind..$^{43}$

The Wikibooks platform gives us the opportunity to recognize and assign credit for important editorial work that extends beyond the creation of original base text. Activities like discussion and feedback are central to scholarly revision and authorship, but can be difficult to monitor and quantify in a large project. A print edition often only acknowledges these forms of labour with a line or two on the acknowledgments page. Originally, we considered the discussion pages ideal for this type of scholarly discussion and editorial record keeping. Like any private community, however, Wikibooks bears its own social

43. Bo Leuf and Ward Cunningham, authors of the first book on wikis, recognize that a wiki must fit the culture of the user community for it to be successful; see The Wiki Way (Boston: Addison-Wesley Professional, 2001). Emma Tonkin advises that a collaborative authoring wiki should include the following: a page locking system to deter simultaneous editing, a versioning system to track changes, and the ability to lock editing on a page in the case of an edit war, as well as an efficient search function, and navigation, categorization, and file management abilities. See "Making the Case for a Wiki," Ariadne 42 (January 2005): n. p., http://www.ariadne.ac.uk/issue42/tonkin. 
conventions. Through conversation with an established Wikibooks editor we realized that the Wikibooks discussion pages are more often used for personal commentary and disputes than editorial suggestions. Reminiscent of Douglas's note in the margin of "Suffryng in sorrow in hope to attyn" (fol. 6v-7r) to "fforget thys," and Shelton's contradiction "yt ys wor[t]hy," these pages are predominantly venues for editors to offer one another personal support (or criticism) rather than to analytically discuss content in a way scholars might find useful in a research context. Although the technology readily supports our original intention, the cultural practices of the Wiki community required us to alter our expectations. Despite this, all edits to all pages of the project are recorded on each page's "View History" tab.

Thus, rather than relying on the discussion pages for editorial debate and decisions, we made the most substantive changes in Wikibooks based on Skype and Iter interactions with our advisory group. Although our hope had been to have the advisors edit directly in Wikibooks, many found the technological threshold for contributing too high, and it became more practical to have the ETCL team make the proposed changes to WikiCode. We responded to the advisors' recommendations in near-real time, adding (among other suggestions) navigation menus and facsimile page images. This is, again, a cultural issue rather than a technical one: the social edition has always been, and remains, open for anyone to edit at any time. Short of locking a page by an administrator (an action often undertaken only for repeated vandalism or during edit wars), there is no mechanism for denying anyone the ability to edit. As we found, many avenues for editorial conversation are necessary in order to foster the sense of a community that, as one of our advisors noted, is "virtually there, as if everyone is crowded around a page, putting their two cents in on matters great and small." Even when those giving editorial direction do not directly make changes to the edition, the use of multiple social media platforms like blogs and Twitter can productively facilitate social editing discussions. Focusing solely on one single communications platform could potentially impede the success of an evolving edition.

As we discovered, every social media platform attracts and enables specific types of interaction. Using social media allows us to integrate a new step into the editorial process - a step that fills the gap between initial planning stages and concluding peer review reports. Producing an edition "live" in consultation with various groups across multiple media engenders an edition that quickly 
and productively meets the needs of its readers. Employing and participating in various platforms alerted us to different priorities across platforms, as well as forced us to think through how we might create a polyvocal experience for safe, productive, and equitable interactions.

In addition to producing an edition that allows for multiple editorial perspectives, the DMSEG gathered responses to the social edition-building methodology. In the interest of refining the process and expounding on its utility for collaborative editors in the Web 2.0 environment, the ETCL team used a combination of methods to gather data on the social edition-building process. We invited feedback via Twitter, guest blog posts, and Iter's social media space. We also encouraged direct intervention in the Wikibook edition of A Social Edition of the Devonshire Manuscript. Furthermore, we consulted with members of our advisory group on issues of credit, peer review, and collaborative decision-making. Rather than soliciting anonymous reader reports from our advisors, we brought them into conversation with one another over the fixed edition and the evolving Wikibook edition. We facilitated this conversation in a social media space housed by Iter, a federated site housed at the University of Toronto that serves a broad community of early modern and Renaissance associations and scholars. ${ }^{44}$ In many cases, their suggestions have already been incorporated into the Wikibooks publication; those that have not will be integrated into a final, socially-produced edition of the Devonshire Manuscript for print and e-publication with Iter and Medieval and Renaissance Texts and Studies (MRTS). ${ }^{45}$

Considered as a whole, A Social Edition of the Devonshire Manuscript suggests that social media technologies can be harnessed for productive interaction and discussion by those scholars invested in a content area or project, but that they require comprehensive oversight by dedicated staff to develop and maintain participation in knowledge construction and dissemination. Regardless,

44. See Iter: Gateway to the Middle Ages and Renaissance, 5 November 2014, http://itergateway.org/.

45. These various avenues of participation met with different levels of success, the overview of which is outside the scope of this article. Our team has presented on this aspect of the project at Digital Humanities 2013 (see http://dh2013.unl.edu/abstracts/ab-300.html), and a forthcoming article focuses more intently on stakeholder communities and their responses to the project. See Constance Crompton, Raymond Siemens, Alyssa Arbuckle, the Devonshire Manuscript Editorial Group, and INKE, "Enlisting 'Vertues Noble \& Excelent' Across Scholarly Cultures: Digital Collaboration and the Social Edition,” Digital Humanities Quarterly (accepted). 
social scholarly editions represent a step toward diversifying and democratizing knowledge, and the Wikimedia suite of platforms is an established environment for this sort of work. Todd Presner reiterates this concept by considering Wikipedia as a model for the future of humanities research, deeming Wikipedia "a truly innovative, global, multilingual, collaborative knowledge-generating community and platform for authoring, editing, distributing, and versioning knowledge." ${ }^{36}$ Larger than a mere technological innovation, wikis represent a change in the philosophy and practice of knowledge creation. Publishing scholarly work in such an environment is a direct intervention into multithreaded conversations maintained by lay knowledge communities on the web and existing scholarly discourses surrounding scholarly editing.

\section{Conclusion: digital affordances for academic and non-academic editing}

The Devonshire Manuscript's social structure and content strongly influenced our choice of Wikibooks as a publication platform. Social media environments that have emerged recently, including the Wikimedia suite itself, reshape the way academic and citizen scholars work by providing new tools and platforms to undertake scholarly activities. These technological innovations can incite academic researchers to open up scholarship and create editions in ways not previously possible or practical. The intersection of social media and scholarly editing has a destabilizing effect, as it prompts models of textual interaction and intervention that represent the scholarly text as a process rather than a product. These significant conceptual shifts in research, writing, and editorial practices have provoked reconsiderations of the ethos and methods inherent to academic scholarship in particular, and knowledge creation in general. For instance, the open source movement has morphed through its open scholarship instantiation to develop a new breed of academic: the open scholar. ${ }^{47}$ According to Terry Anderson, open scholars "create; use and contribute open educational resources; self archive; apply their

46. Todd Presner, "Digital Humanities 2.0: A Report on Knowledge," Connexions (revised 8 June 2010), n.p. http://cnx.org/contents/2742bb37-7c47-4bee-bb34-0f35bda760f3@6/Digital_Humanities_2.0:_A_Repo.

47. Don Tapscott and Anthony D. Williams outline five levels of open scholarship: (1) course content exchange; (2) course content collaboration; (3) course content co-innovation; (4) knowledge co-creation; and (5) collaborative learning connection. "Innovating the 21st-Century University: It's Time!" Educause (January/February 2010): 22. 
research; do open research; filter and share with others; support emerging open learning alternatives; publish in open access journals; comment openly on the works of others; [and] build networks." ${ }^{48}$ The website Academia.edu illustrates this open scholarship, as many of the site's users upload their own work-often in direct contravention of copyright agreements with publishers-and promote its direct dissimination to new readers without recourse to periodically published print journals. Openness as a scholarly virtue requires adopting values that the nature and scale of the electronic medium necessitates: i.e., collaboration and innovation across backgrounds, skill levels, and disciplines. ${ }^{49}$ These concepts vary considerably from the closed publication processes and professional cultures that have traditionally typified knowledge creation within the academy.

Technological advances potently shape how individuals and communities create new knowledge. It behooves scholars to think through the affordances and implications of any collaborative publishing platform, space for social knowledge creation, or multi-authored environment. Incorporating social media and Web 2.0 practices into scholarly editing recasts the primary editor as a facilitator rather than progenitor of scholarly editions. Conventionally, a single editor determines and shapes what is important to a passive reader, focuses the editorial and analytical lens, and ultimately exerts immense control over reader experience. A social media framework for the electronic scholarly edition pushes the boundaries of this authority, shifting power from a single editor to a community of active readers and mediators. As Kathleen Fitzpatrick writes, introducing different modes of reading and interpreting that take advantage of the capabilities of digital networks allows for new knowledge to develop:

48. In Mahony, n.p. Fred Garnett and Nigel Ecclesfield discuss the Open Scholar philosophy further in "Towards a Framework for Co-Creating Open Scholarship," Research in Learning Technology 19 (2012), n.p. Not to be confused with the Drupal software Open Scholar. Garnett and Eccles reference Academic Evolution, a blog formerly run by Gideon Burton, who states: "the Open Scholar is someone who makes their intellectual projects and processes digitally visible and who invites and encourages ongoing criticism of their work and secondary uses of any or all parts of it at any stage of its development" (n. p).

49. Looking further than a mere series of activities, Charles M. Vest predicts the development of a metauniversity: "a transcendent, accessible, empowering, dynamic, communally constructed framework of open materials and platforms on which much of higher education worldwide can be constructed or enhanced." See “Open Content and the Emeriging Global Meta-University," Educause (May/June 2006): 8. 
Scholars operate in a range of conversations, from classroom conversations with students to conference conversations with colleagues; scholars need to have available to them not simply the library model of texts circulating amongst individual readers but also the coffee house model of public reading and debate. This interconnection of individual nodes into a collective fabric is, of course, the strength of the network, which not only physically binds individual machines but also has the ability to bring together the users of those machines, at their separate workstations, into one communal whole. ${ }^{50}$

The social edition models a new kind of scholarly discourse network that hopes to eschew traditional, institutionally reinforced, hierarchical structures and relies, instead, upon those that are community-generated.

A Social Edition of the Devonshire Manuscript brings communities together to engage in conversation around a text formed and reformed through an ongoing, iterative, public editorial process. A central aim of the project is to facilitate knowledge transfer and creation between multiple editorial communities with varying values and priorities. Siemens and others have elsewhere called for scholars "to extend our understanding of the scholarly edition in light of new models of edition production that embrace social networking and its commensurate tools... [to develop] the social edition as an extension of the traditions in which it is situated and which it has the potential to inform productively." ${ }^{51}$ Bringing practice to theory, we have attempted to model the digital, social, scholarly edition. We have worked as a team to extend scholarly best practice and open access ideas to collaborative Web 2.0 environments. By privileging process over end result, the DMSEG aims to render transparent the production of an online edition of the Devonshire Manuscript.

A Social Edition of the Devonshire Manuscript is, at the same time, designed to fill the void that Ezell notes has been left by the "little effort [that] has been made to catalogue and reconstruct patterns in women's manuscript texts to provide an inclusive overview of literary activities rather than isolated, individual authors." 52 The DMSEG also planned the form of the social edition

50. Kathleen Fitzpatrick, “CommentPress: New (Social) Structures for New (Networked) Texts," Journal of Electronic Publishing 10.3 (2007): n. p. DOI: http://dx.doi.org/10.3998/3336451.0010.305.

51. Siemens et al., "Toward Modeling the Social Edition," 447.

52. Ezell, Social Authorship, 23. 
in response to Greg Crane and others' exhortation that " $[w] e$ need to shift from lone editorials and monumental editions to editors [...] who coordinate contributions from many sources and oversee living editions." 53 The editorial communities that have grown up around social media sites like Wikibooks indicate a public desire to expand knowledge communities using accessible social technologies.

Such goals resonate with other digital projects undertaken around the turn of the century. In Great Britain, the century-old Oxford Dictionary of National Biography (ODNB) was republished as an extensively updated online database in 2003, an effort that involved numerous contributors and a large dedicated team. ${ }^{54}$ In Canada, digital projects were undertaken that were dedicated to reconceptualizing how we investigate early modern society and culture. Orlando: Women's Writing in the British Isles from the Beginnings to the Present, ${ }^{55}$ developed at the University of Alberta and currently published electronically and in print by Cambridge University Press, is a dynamic textbase including over eight million words and ranging widely in topic, is a case in point. Although not limited to the English Renaissance, The Orlando Project, much like the more general $O D N B$, provides a staggering amount of information on women writers' lives, careers, works, and communities. In doing so, however, it explicitly figures itself as "an unprecedented work of literary scholarship" that is not a book, "though in length the equivalent of about 80 scholarly books, and not a digital edition of an existing text." ${ }^{\text {"W }}$ While in many ways different from A Social Edition of the Devonshire Manuscript, The Orlando Project attempts to push the boundaries of how digital tools might improve the foundational tools of scholarship. What The Orlando Project and Wikipedia do for the encyclopedia in a world of densely networked information, A Social Edition of the Devonshire Manuscript does for the scholarly edition.

As projects like Orlando expand the ways we build, use, and reflect on the foundational information that allows for literary criticism, projects like

53. Greg Crane, "Give Us Editors! Re-inventing the Edition and Re-thinking the Humanities," in The Shape of Things to Come (Charlottesville, VA: March 2010), n. p.

54. Brian Harrison, “The Sequence of Production; Progress of the Project, 1992-2004; Outcomes," Oxford Dictionary of National Biography (2004), http://global.oup.com/oxforddnb/info/print/intro/intro5/.

55. The Orlando Project, 5 November 2014, http://www.artsrn.ualberta.ca/orlando/.

56. Patricia Clements, Isobel Grundy, and Susan Brown, "What is Orlando?" The Orlando Project (2010), http://www.artsrn.ualberta.ca/orlando/?p=2658. 
ArchBook: Architectures of the Book help us to critique the medium of publication itself. ${ }^{57}$ ArchBook originated in INKE and is now hosted by the University of Saskatchewan's Humanities and Fine Arts Digital Research Centre. Consisting of encyclopedic, peer-reviewed, and illustrated articles on specific design features, ArchBook highlights the historical development of various features of the book. In a similar stream, many decisions during the development of $A$ Social Edition of the Devonshire Manuscript were in fact made with a distinct appreciation for what the medium of Wikibooks and the form of the edition called for. Paratextual materials were determined by which elements of the book, historically construed, our team identified as most valuable to diverse end-users. Moreover, the dynamic table of contents in A Social Edition of the Devonshire Manuscript attempts, via its design, to respond to the needs and historically formed expectations of scholars.

Our edition building process and subsequent critical reflection were, therefore, situated at the intersection of multiple vectors of Canadian digital humanities, the history of the book, the rise of social knowledge creation, and the growing cross-fertilization of academic and wiki culture. It is our hope that this model of the social scholarly edition successfully brings together various communities of scholars and modes of creating and disseminating knowledge. In developing an edition that carries forward early production, authoring, and circulation mores, A Social Edition of the Devonshire Manuscript enacts textual ideas of the socially produced text. A Social Edition of the Devonshire Manuscript is one of a range of possibilities for digital, social, scholarly editing across contemporary editorial communities-communities that need not be limited by social, geographic, or institutional boundaries.

57. Alan Galey, ed., Archbook: Architectures of the Book, 5 November 2014, drc.usask.ca/projects/ archbook/. 